\title{
Arginine inactivates human herpesvirus 2 and inhibits genital herpesvirus infection
}

\author{
KEIKO IKEDA ${ }^{1,3}$, HISASHI YAMASAKI ${ }^{1}$, SAWAKO MINAMI ${ }^{2}$, YUKIKO SUZUKI ${ }^{3}$, KAZUKO TSUJIMOTO ${ }^{4}$, \\ YOSHIHISA SEKINO ${ }^{5}$, HIROSHI IRIE ${ }^{6}$, TSUTOMU ARAKAWA $^{7}$ and A. HAJIME KOYAMA ${ }^{1,4}$ \\ ${ }^{1}$ Department of Cellular and Molecular Medicine, Division of Virology and ${ }^{2}$ Department of Reproductive and \\ Developmental Medicine, Division of Reproductive Medicine, Wakayama Medical University Graduate School of Medicine; \\ ${ }^{3}$ School of Health and Nursing Science, Wakayama Medical University, Wakayama 641-8509; \\ ${ }^{4}$ Wakayama Shin-ai Women's Junior College, Wakayama 640-0341; ${ }^{5}$ Department of Anatomy, School of Medicine and \\ ${ }^{6}$ Department of Sport and Medical Science, School of Medical Technology, Teikyo University, Itabashi 173-8605, Japan; \\ ${ }^{7}$ Alliance Protein Laboratories, Thousand Oaks, CA 91360, USA
}

Received June 11, 2012; Accepted August 21, 2012

DOI: 10.3892/ijmm.2012.1149

\begin{abstract}
Arginine, among the amino acids, has demonstrated unique properties, including suppression of protein-protein interactions and virus inactivation. We investigated the effects of arginine on the infectivity of human herpesvirus 2 (HHV-2) and the potential application of arginine as a chemotherapeutic agent against genital herpes. Arginine directly inactivated HHV-2 and characterization of the inactivation demonstrated that $1 \mathrm{M}$ arginine at $\mathrm{pH} 4.3$ inactivated the virus more efficiently compared to $0.1 \mathrm{M}$ citrate or $1 \mathrm{M}$ sodium chloride, indicating that neither acidic $\mathrm{pH}$ nor ionic strength alone is sufficient for virus inactivation. The effect of arginine was rapid and concentration-dependent. Although virus inactivation was efficient at an acidic $\mathrm{pH}$, arginine inactivated the virus even at a neutral $\mathrm{pH}$, provided that a higher arginine concentration and prolonged incubation time were used. In addition, arginine suppressed the multiplication of HHV-2 under the conditions at which its effect on cell viability was insignificant. Pilot mouse model studies revealed a marked suppression of death by arginine when the mice were infected with HHV-2 through the vaginal route, followed by an intermittent application of acidic arginine by vaginal instillation.
\end{abstract}

\section{Introduction}

Arginine is one of the most common 20 natural amino acids and is semi-essential for the human body, carrying a unique long carbon-containing side chain with a complex

Correspondence to: Professor A. Hajime Koyama, Wakayama Shin-ai Women's Junior College, 702-2 Souzaka, Wakayama 640-0341, Japan

E-mail:koyama@shinai-u.ac.jp

Key words: arginine, antiviral, virucidal, human herpesvirus 2, genital herpes guanidinium group at the end. Characterization of the interaction of this amino acid with proteins has revealed that, compared to other amino acids, arginine is unique in that it enhances the solubility of proteins and small organic compounds (1). An additional novel property of arginine is its ability to inactivate a variety of viruses, depending on the concentration, incubation $\mathrm{pH}$ and temperature (2-5). The systematic characterization of the effect of arginine on DNA and RNA viruses revealed that arginine or its derivative was effective in inactivating several enveloped viruses of different families, including human herpesvirus 1 (HHV-1, a member of the Herpesvirus family), influenza A virus (a member of the Orthomyxovirus family) and Sendai virus (a member of the Paramyxovirus family). However, it was incapable of inactivating non-enveloped poliovirus (a member of the Picornavirus family). Unexpectedly, one enveloped virus, i.e., Newcastle disease virus (NDV; a member of the Paramyxovirus family), was observed not to be inactivated by these reagents, indicating that not all enveloped viruses were sensitive to arginine (6).

Virus inactivation using various solvent systems is a critical technology for the reduction of virus load on contaminated surfaces and in pharmaceutical products (7). However, this type of technology is not normally applicable to the therapeutic treatment of viral diseases due to its strong tissue toxicities. In this regard, arginine, being a natural metabolite, may be applied as a more effective virucidal agent in vivo, in particularly against superficial virus infections at the body surface, such as upper respiratory infections and herpetic keratitis $(8,9)$. In addition to its virucidal effects, arginine affects the multiplication of HHV-1 at concentrations far below the concentration at which it exerts virucidal activity and cytotoxicity (10). Thus, arginine may suppress HHV-1 infection through both virucidal and antiviral activities. In fact, a preliminary study reported that arginine significantly inhibited the development of herpetic keratitis in a rabbit eye model (Naito et al, unpublished data). In the present study, we examined the virucidal and antiviral activities of arginine 
against human herpesvirus 2 (HHV-2, also known as herpes simplex virus type 2 or HSV-2), which is responsible for genital infection, the most common causes of genital ulcer disease worldwide. HHV-2 establishes latent infection in the neuronal cells in ganglia after initial infection, remaining dormant in the infected cells for a lifelong period and causes an asymptomatic virus shedding or symptomatic vesicle and ulcer formation on the mucosal surfaces of the genital organs during recurrences (11). Considering in vivo application of arginine against genital herpes, we have characterized the virucidal effects of arginine against HHV-2 near body temperature (5). Based on observation of the excellent virucidal activities of arginine, we then examined arginine for its ability to suppress HHV-2 genital infection using a mouse model.

\section{Materials and methods}

Cells and viruses. HEp-2 and Vero cells were grown in Eagle's minimum essential medium (MEM) containing $5 \%$ fetal bovine serum (FBS). HHV-2, strain 186, was used throughout the experiments. HHV-2 was propagated in Vero cells cultured in MEM supplemented with $0.5 \%$ FBS. The virus was stored at $-80^{\circ} \mathrm{C}$ until use. The amount of virus was measured by a plaque assay on Vero cells as previously described $(12,13)$.

Reagents. L-arginine hydrochloride (simply described as arginine) was obtained from Ajinomoto Co., Inc. Aqueous solutions containing arginine or $\mathrm{NaCl}$ were prepared in $20 \mathrm{mM}$ acetic acid. The $\mathrm{pH}$ of the arginine solutions was adjusted to the indicated values with $\mathrm{HCl} ; 20 \mathrm{mM}$ acetic acid is insufficient to titrate arginine solution to the desired $\mathrm{pH}$. The $\mathrm{pH}$ of the $\mathrm{NaCl}$ in $20 \mathrm{mM}$ acetic acid and aqueous citrate solutions was adjusted to the indicated $\mathrm{pH}$ with $\mathrm{NaOH}$. The $\mathrm{pH}$ meter was routinely calibrated using $\mathrm{pH}$ calibration standards.

Assay for virucidal activity. All the starting materials were stored on ice prior to the virus inactivation experiments. A $190 \mu \mathrm{l}$ aliquot of the solutions to be evaluated was placed in $2.0-\mathrm{ml}$ plastic tube on ice and received $10 \mu \mathrm{l}$ of virus preparation [approximately $10^{8}$ plaque-forming units (PFU)/ml)]. This was immediately followed by vigorous mixing and the sample mixture was incubated at the indicated temperatures. After the incubation, aliquots of these virus samples were 100-fold diluted with Dulbecco's phosphate-buffered saline (PBS) without $\mathrm{Ca}^{2+}$ and $\mathrm{Mg}^{2+}$ containing $0.5 \%$ FBS to terminate the virucidal action of the solutions. This dilution step helped stabilize the infectivity of the surviving viruses after the inactivation treatment. The viruses were further diluted with ice-cold PBS containing $0.5 \%$ FBS and the number of infectious viruses in the treated preparation was measured by a plaque assay on Vero cells. All the experiments were conducted in duplicate or triplicate.

Virus yields in the presence of arginine. The effect of arginine on the multiplication of HHV-2 was examined as follows. The monolayered HEp-2 cells in 35-mm dishes were infected with the virus at an indicated multiplicity of infection (MOI). The infected cells were further incubated at $37^{\circ} \mathrm{C}$ for the indicated period in the serum-free MEM containing $0.1 \%$ bovine serum albumin (BSA) and in the indicated concentrations of arginine. At the end of the incubation, the amounts of progeny virus in the infected cultures were determined as previously described (14). Briefly, after two or three cycles of freezing and thawing the infected cells along with the culture media, the number of infectious viruses in the lysate was measured by a plaque assay.

Determination of cytopathic effects and the cell death. The cytopathic effects (CPEs) were determined by microscopic observation of the cells; approximate amounts of rounded cells on monolayers were estimated under a phase-contrast microscope. The extent of cell death in the cultures was determined as follows. The monolayerd cells were trypsinized to obtain a single cell suspension. After the addition of MEM containing $5 \%$ FBS to the suspension to neutralize trypsin and stabilize the cells, the numbers of living and dead cells were measured by a dye-exclusion method with trypan blue (15).

Murine experiments. Seven-week-old female BALB/c mice were infected with HHV-2 as follows. The mice, whose vaginal walls were scratched, were infected with $6 \times 10^{5} \mathrm{PFU}$ HHV-2 in $10 \mu \mathrm{l}$ by vaginal instillation. For the treatment with test solutions, the mice were treated with $20 \mu \mathrm{l}$ of the indicated solutions by vaginal instillation at 2,12 and $24 \mathrm{~h}$ post-infection (h p.i.) and then once every day for 20 days. In case of acycloguanosine, it was administrated daily intraperitoneally at a dose of $0.05 \mathrm{mg} / 200 \mu \mathrm{l} / \mathrm{head}$. The number of mice that survived and the symptoms of these infected mice were examined daily. All animal experiments were performed in compliance with the principles of laboratory animal care (NIH publication No. 86, revised 1985) and with the guidelines of Teikyo University School of Medicine Animal Experiments Committee.

\section{Results}

Effect of arginine on the inactivation of $H H V$-2. Previously we observed that arginine and arginine derivatives are effective in inactivating a variety of enveloped viruses, although a number of them, such as NDV, are not sensitive to arginine (6). When HHV-2 was incubated with mildly acidic arginine solution, this virus was also sensitive to arginine (Fig. 1). Incubation of the virus with $1.0 \mathrm{M}$ arginine at $\mathrm{pH} 4.3$ at $30^{\circ} \mathrm{C}$ for $10 \mathrm{~min}$ reduced the infectivity to less than one-thousandth the level of the PBS control, while $0.1 \mathrm{M}$ citrate at the same $\mathrm{pH}$ revealed marginal inactivation ( 0.25 relative to the PBS control) and 0.7 and $1.0 \mathrm{M}$ sodium chloride solutions at the same $\mathrm{pH}$ were not effective. These results clearly indicate that mildly acidic arginine effectively inactivates $\mathrm{HHV}-2$ and that neither the acidic $\mathrm{pH}$ nor the high salt concentration was effective. This inactivation by arginine was concentration-dependent, since $0.7 \mathrm{M}$ arginine solution reduced the infectivity to only onehundredth the level of the PBS control (Fig. 1). A comparison with other viruses indicates that HHV-2 is the most sensitive virus examined thus far (data not shown).

The rate of the virus inactivation was much faster with arginine. HHV-2 revealed no noticeable inactivation in the PBS during $20 \mathrm{~min}$ of incubation on ice (Fig. 2). In both 


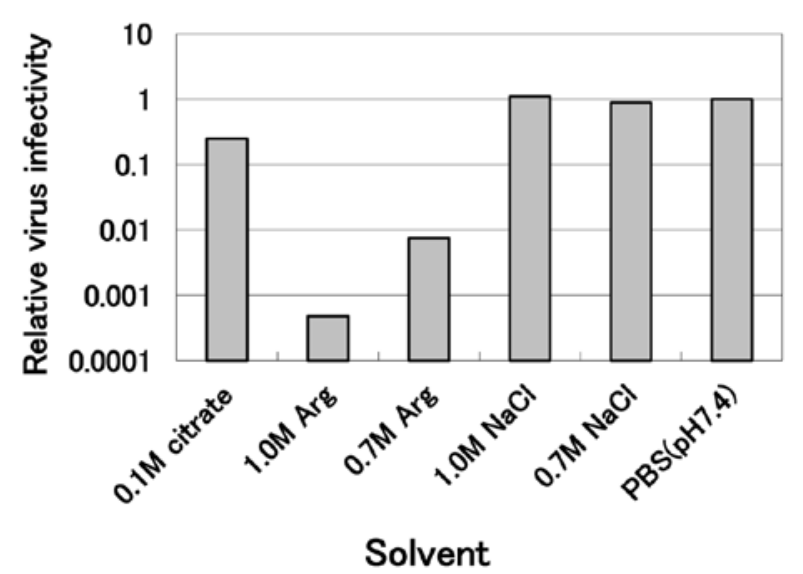

Figure 1. Effect of arginine on the infectivity of HHV-2. The virus was incubated at $30^{\circ} \mathrm{C}$ for $10 \mathrm{~min}$ in the indicated solutions. The $\mathrm{pH}$ of the solutions was adjusted to 4.3, except for PBS (pH 7.4). The numbers of infectious viruses after the incubation were determined by a plaque assay and were normalized to those in PBS.

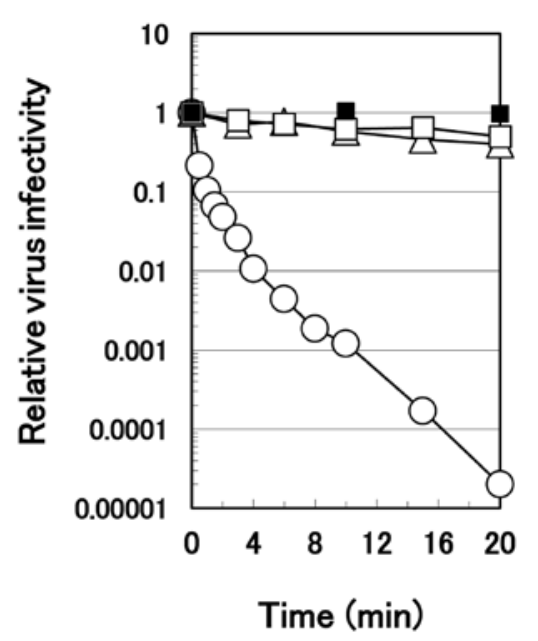

Figure 2. Time course of the inactivation of HHV-2 by arginine. The virus was incubated on ice for the indicated periods in $1.0 \mathrm{M}$ arginine at $\mathrm{pH} 4.3(\mathrm{O}), 0.1 \mathrm{M}$ sodium citrate at $\mathrm{pH} 4.3(\triangle), 1.0 \mathrm{M} \mathrm{NaCl}$ at $\mathrm{pH} 4.3(\square)$ or PBS ( $(\mathbf{)})$. The numbers of infectious viruses after the incubation were determined by a plaque assay and were normalized to those in PBS.

1.0 $\mathrm{M}$ sodium chloride and $0.1 \mathrm{M}$ citrate solutions at $\mathrm{pH} 4.3$, the virus was inactivated only slightly with time at the same temperature. Conversely, the virus inactivation occurred rapidly in $1.0 \mathrm{M}$ arginine solution at $\mathrm{pH} 4.3$; it decreased in monotone with time, reaching one-thousandth the level of the PBS control at $10 \mathrm{~min}$ of the incubation on ice and approximately $10^{-5}$ at 20 min of the incubation.

We previously demonstrated that the ability of arginine and citrate to inactivate HHV-1 diminishes rapidly when the $\mathrm{pH}$ of the solution was increased (2). The effect of $\mathrm{pH}$ on the inactivation of HHV-2 by $0.1 \mathrm{M}$ citrate or $0.7 \mathrm{M}$ arginine is displayed in Fig. 3. To compensate for the difference in ionic strength between these two solutions, $0.6 \mathrm{M}$ sodium chloride was added to the series of $0.1 \mathrm{M}$ citrate. At or below $\mathrm{pH} 4.0$, all three solutions equally and efficiently inactivated HHV-2. Above $\mathrm{pH}$ 4.0, $0.1 \mathrm{M}$ citrate solution by itself or supplemented with $0.6 \mathrm{M}$ sodium chloride lost the ability to inactivate the

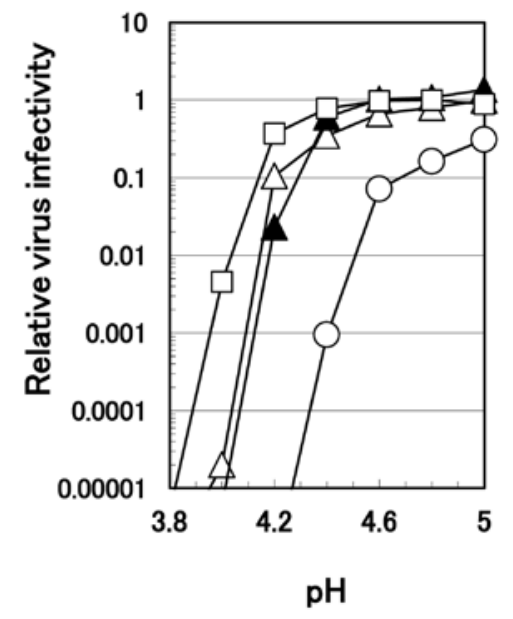

Figure 3. Effect of pH levels of the solutions on the inactivation of HHV-2. The virus was incubated on ice for $60 \mathrm{~min}$ in $0.7 \mathrm{M}$ arginine $(0), 0.1 \mathrm{M}$ citrate $(\triangle), 0.1 \mathrm{M}$ citrate supplemented with $0.6 \mathrm{M} \mathrm{NaCl}(\Delta)$ or $0.7 \mathrm{M}$ citrate ( $\square$ ). The $\mathrm{pH}$ of the solutions was adjusted to the indicated $\mathrm{pH}$. The numbers of infectious viruses after the incubation were determined by a plaque assay and were normalized to those in PBS.

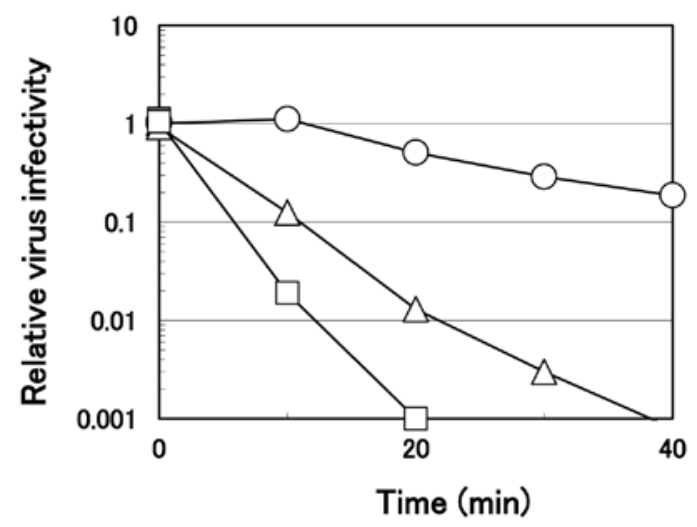

Figure 4. Effect of neutral arginine solution on the infectivity of HHV-2. The virus was incubated on ice for the indicated periods in $0.75 \mathrm{M}$ arginine at $\mathrm{pH} 7.0(\mathrm{O}), 1.0 \mathrm{M}$ arginine at $\mathrm{pH} 7.0(\triangle)$ or $1.2 \mathrm{M}$ arginine at $\mathrm{pH} 7.0(\square)$. The numbers of infectious viruses after the incubation were determined by a plaque assay and were normalized to those in PBS without the incubation.

virus to a much greater extent than $0.7 \mathrm{M}$ arginine; $0.7 \mathrm{M}$ arginine reduced virus infectivity below the detection level even at $\mathrm{pH}$ 4.2. A higher concentration of citrate at $0.7 \mathrm{M}$ was least effective, possibly due to the salting-out effect of citrate that protected the virus from the inactivation, as discussed previously (5). Differences in the degree of virus inactivation among different solutions decreased at higher $\mathrm{pH}$, e.g., above 4.6.

Virucidal effect of arginine at a neutral $\mathrm{pH}$. As described above, virucidal activity of arginine was much weaker at a higher $\mathrm{pH}$. However, even at a neutral $\mathrm{pH}$, a prolonged incubation time resulted in significant inactivation. The time course of the virus inactivation on ice by arginine at $\mathrm{pH} 7.0$ is displayed in Fig. 4. Consistent with the results shown in Fig. 1, the ability depended an arginine concentration. HHV-2 was inactivated quickly with arginine solution at $1.2 \mathrm{M}$, reaching one-thousandth within $20 \mathrm{~min}$ of the incubation while the 


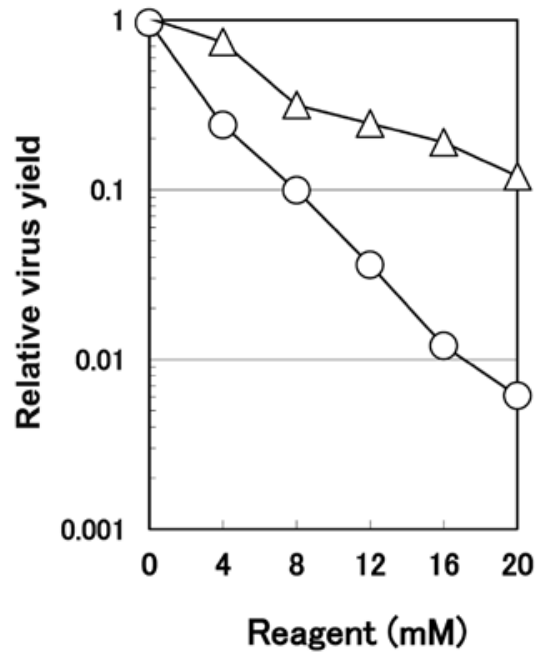

Figure 5. Effect of arginine on the progeny virus yield in HHV-2-infected HEp-2 cells. Confluent monolayers of HEp-2 cells were infected with $\mathrm{HHV}-2$ at an MOI of 10 . The infected cells were incubated at $37^{\circ} \mathrm{C}$ for approximately $46 \mathrm{~h}$ in the MEM containing $0.1 \%$ BSA and the indicated concentrations of arginine $(0)$ or sodium chloride $(\Delta)$. The amounts of total progeny viruses were determined as described in Materials and methods and were normalized to the virus yield in the absence of the reagent.

virus infectivity decreased slightly, although significantly (only 50-60\% of the PBS control), in $0.75 \mathrm{M}$ arginine solution. At $1.0 \mathrm{M}$, arginine at $\mathrm{pH} 7.0$ inactivated the virus more effectively compared to that at $0.75 \mathrm{M}$, but less effectively compared to that at $1.0 \mathrm{M}$ arginine at $\mathrm{pH} 4.3$ (Fig. 2), reaching one hundredth the level of the PBS control at $20 \mathrm{~min}$ of the incubation. These results clearly reveal that, even at a neutral $\mathrm{pH}$, arginine inactivates HHV-2, provided that higher arginine concentration and a longer incubation time were employed than those at an acidic $\mathrm{pH}$.

Suppression of virus multiplication by arginine. From the results described above, it is evident that arginine directly inactivates HHV-2 in the test tube. Next, we examined the effects of arginine on the virus multiplication in infected cells by incubating HHV-2-infected HEp-2 cells with arginine at various concentrations. The progeny virus yield as a function of arginine concentration (note that the arginine concentration is $\mathrm{mM}$, not $\mathrm{M}$ as in the virus inactivation experiments) is displayed in Fig. 5. Arginine reduced the virus yield dosedependently in the infected cells, reaching one-hundredth the yield of the control untreated culture at $16 \mathrm{mM}$. As a control of ionic strength of arginine, the effects of sodium chloride were examined. As shown in Fig. 5, sodium chloride also concentration-dependently inhibited the multiplication of HHV-2, but to a much smaller extent than the level achieved by arginine. Although HHV-2 is closely related to HHV-1, HHV-2 is more sensitive to arginine than is HHV-1; only $1-\log$ reduction of the relative virus yield was observed for HHV-1 in the presence of arginine at $25 \mathrm{mM}$ (10). Although the arginine concentration is not within a physiological level, it is considered to be within a tolerable range for the infected cells, as described in the following section (i.e., cytotoxic effects of arginine).

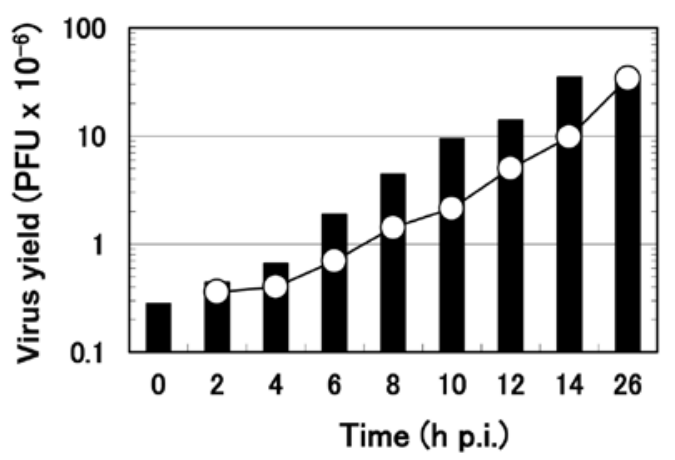

Figure 6. Effect of the time of addition of arginine on the virus yield. A group of confluent monolayers of HEp-2 cells was infected with HHV-2 at an MOI of 14 and was incubated in MEM containing $0.1 \%$ BSA. At the indicated time after the infection, the infected culture in one dish was harvested and the amount of the infectious virus was determined to reveal a one-step growth curve (open circle). Arginine was added to the culture medium in another dish at the final concentration of $30 \mathrm{mM}$; then, the infected cells were further incubated in the presence of arginine and the total progeny virus in each culture was harvested at $26 \mathrm{~h}$ p.i. to determine the amount of the final virus yield (black bar). h p.i., hours post-infection.

It should be noted that the antiviral activity of arginine described above has no relation to the observed direct virucidal activity of arginine, as observed at higher concentrations required to inactivate the virus (Figs. 1-4). Thus, these antiviral effects of arginine are not mediated by virucidal activity, but rather by other factors.

Cytotoxic effects of arginine. Arginine induced notable morphological alterations in HEp-2 cells which included both rounding and shrinkage of the cells, but without cell detachment from the dishes. CPEs were enhanced with increasing concentrations of arginine and, at the concentration of $20 \mathrm{mM}$, arginine induced the CPEs in a small, but significant population of uninfected HEp-2 cells. However, we previously demonstrated, that upon incubation of HEp-2 cells with arginine for $26 \mathrm{~h}$, the cell death was induced only by a small (2-5\%) fraction of the total cell population independently of arginine concentrations $(0-40 \mathrm{mM})$, a magnitude similar to the cell death observed in the sodium chloride-treated cells at the same concentrations (10). These results suggest that the observed decrease in the virus yield by arginine is unlikely due to the degeneration (cell death) of the infected cells by arginine. This suggestion is further confirmed by the observations that the infection with HHV-2 completely abolished arginine-induced CPEs: namely, arginine does not induce CPEs in HEp-2 cells infected with HHV-2, possibly due to the expression of anti-apoptotic genes of HHV-2 in the infected cells (16).

Effect of the time of addition of arginine on the progeny virus yield. A previous characterization of the kinetics of the viral multiplication process in HHV-infected Vero cells (17) revealed that viral DNA replication occurs exclusively between 3 and $6 \mathrm{~h}$ p.i and a large amount of DNA is accumulated in the infected cells when the replication of virus DNA is completed. The formation of nucleocapsids as well as the envelopment of the nucleocapsids begins at $5 \mathrm{~h}$ p.i. 
simultaneously with the formation of infectious progeny virus and continues until approximately $12 \mathrm{~h}$ p.i. In HEp-2 cells, the onset as well as the completion of the formation of the progeny virus is slightly delayed and a small but significant degree of the progeny virus formation continues even after $12 \mathrm{~h}$ p.i., compared with those in Vero cells (Koyama, unpublished data).

To examine the arginine-sensitive step in the multiplication process of HHV-2 in HEp-2 cells, the 'time of addition' experiment was performed. Arginine was added to the infected culture at various times after the onset of $\mathrm{HHV}-2$ multiplication, and the virus yield at $26 \mathrm{~h}$ p.i. was compared to the amount of virus formed in the infected cells at the time of addition of arginine (Fig. 6). The formation of the progeny virus was almost immediately suppressed by the addition when the infected cells received arginine at 0,2 or $4 \mathrm{~h}$ p.i., as noted in small additional increases of the virus yield. In contrast, when arginine was added at or after $6 \mathrm{~h}$ p.i., the suppression in the progeny virus formation was evident but not complete; the formation of the progeny virus continued for a short time after arginine addition. For example, the amount of the infectious virus at $8 \mathrm{~h}$ p.i. was $1.42 \times 10^{6}$. When arginine was added at this time point and cell culture was continued for $26 \mathrm{~h}$, the final virus yield was $4.4 \times 10^{6}$, meaning that the progeny virus formation continued after the addition to a significant extent. However, this virus yield $\left(4.4 \times 10^{6}\right)$ was less than the virus yield without arginine addition $\left(35 \times 10^{6}\right)$, although it was more than 3 -fold higher than the amount of the infectious virus formed at $8 \mathrm{~h}$ p.i. $\left(1.42 \times 10^{6}\right)$. A similar result was obtained from the previous 'time of addition experiment' with HHV-1 (10) and an additional characterization of the one-step growth of HHV-1 revealed that the formation of the progeny virus in the HHV-1-infected HEp-2 cells continued normally for 3-4 h after the addition of arginine and then stopped (10). Both the current and the previous results involving HHV-1 agree with the conclusion that the formation of the progeny virus remains sensitive to arginine in the late stage $(6,8,10$ and $12 \mathrm{~h}$ p.i.) of the infection, even after the completion of the viral DNA replication and the formation of nucleocapsids. However, it should be noted that our results do not exclude the possible arginine-sensitive step in the early stages ( 2 and $4 \mathrm{~h}$ p.i.) of the HHV infection.

Effect of arginine on the infection through the genital route. The in vitro studies as described above clearly indicate the antiviral and virucidal activities of arginine against HHV-2 infection. Although both of these activities require higher arginine concentration than the physiological level, we carried out a pilot study to examine the potential application of arginine as a therapeutic or preventive medicine in vivo. Mouse genital herpes infection was used as a model disease for the treatment with arginine, since arginine at high concentrations is not tolerable for an in vivo systemic application but can be used to treat superficial virus infection on the body surface.

$\mathrm{BALB} / \mathrm{c}$ mice are very sensitive to $\mathrm{HHV}-2$ following infection through the vaginal route; the virus first multiplies at the site of infection in the vagina, followed by invasion into the central nervous system through sacral ganglia neuronal cells, and finally causes lethal encephalitis at the brain stem. To examine arginine as a possible treatment for genital herpes

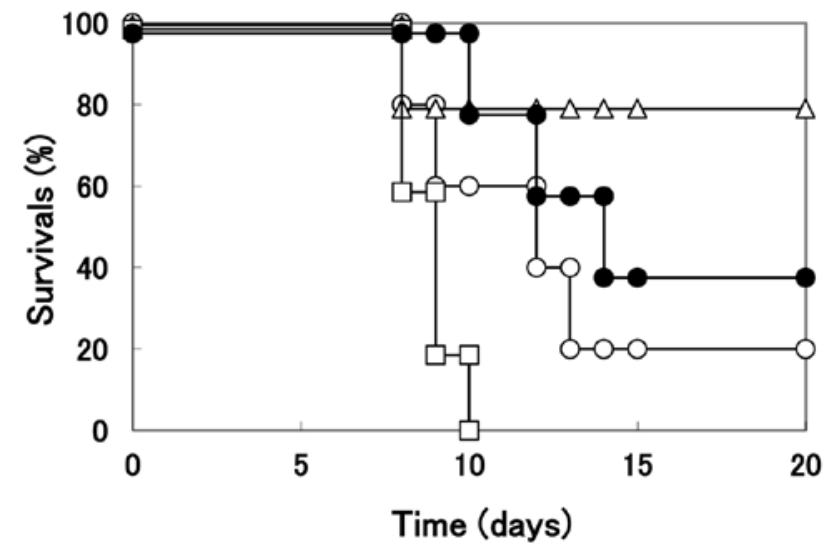

Figure 7. Effect of arginine on the establishment of HHV-2 infection in mice through the genital route. Five mice/group of 6- to 8-week-old female BALB/c mice were infected with $10^{5}$ PFU HHV-2 in $10 \mu 1$ by vaginal instillation. The infected mice were treated daily as described in Materials and methods by the vaginal instillation with $20 \mu \mathrm{l}$ ofPBS (O), $1.0 \mathrm{M}$ arginine at pH $3.8(\triangle), 0.1 \mathrm{M}$ citrate $(\square)$ or $0.6 \mu \mathrm{g}$ acycloguanosine $(\bullet)$. Numbers of dead and living mice were scored daily.

infection, we examined the effects of acidic arginine on the establishment of HHV-2 infection in a mouse model. To ensure the virus infection, the vaginal walls of the mice were scratched before inoculation with HHV-2. Two hours after the inoculation, the mice received $20 \mu \mathrm{l}$ arginine solution by vaginal instillation according to the schedule described in Materials and method. Considering a potential dilution of the arginine solution by vaginal secretion, arginine at slightly higher concentrations and a lower $\mathrm{pH}$ was used in this in vivo study compared to those used in the in vitro studies described above.

When the infected mice were treated with PBS (control without arginine treatment), the mortality of mice was noted at 8 days p.i. and the number of surviving mice was 1 out of 5 at 20 days p.i. (Fig. 7). However, when the infected mice were treated with arginine solution $(\mathrm{pH} 3.5)$, only one mouse died at 8 days p.i., with four mice surviving until 20 days p.i. In contrast to the infected mice treated with arginine, those treated with citrate buffer at the same $\mathrm{pH}$ began to die at 8 days p.i., and all infected mice died by 10 days p.i.. Although acycloguanosine is known to be an effective antiviral drug for human HSV infections, this medicine is toxic to BALB/c mice and treatment with this compound may not rescue mice from the infection. The number of surviving mice was almost similar to those treated with PBS, although the mice treated with acycloguanosine began to die at 10 days p.i. and the mice treated with PBS began to die at 8 days p.i. It should be noted that no apparent tissue damage was observed in the genital organs following arginine treatment. These results clearly indicate that the arginine treatment may effectively rescue mice from the infection of HHV-2 through the vaginal route and suggest a potential use of arginine as a preventive medicine against genital HHV-2 infection.

\section{Discussion}

The present study clearly showed the ability of arginine to inactivate HHV-2 and suppress its growth. The characterization 
of virus inactivation by arginine revealed the following, i) at $\mathrm{pH} 4.3,1.0 \mathrm{M}$ arginine more efficiently inactivated the virus than $0.1 \mathrm{M}$ citrate or $1.0 \mathrm{M}$ sodium chloride (Figs. 1 and 2), indicating that neither acidic $\mathrm{pH}$ nor ionic strength alone was sufficient for HHV-2 inactivation and ii) while the inactivation was more efficient at an acidic pH (Fig. 3), arginine at a neutral $\mathrm{pH}$ was capable of inactivating the virus, in particular at higher arginine concentrations and with a prolonged incubation time (Fig. 4). iii) The rate of virus inactivation was dependent on arginine concentrations (Figs. 1 and 4), pH (Fig. 2) and temperature (data not shown). These characteristics of HHV-2 inactivation by arginine are similar to those observed for HHV-1 (2,3), although HHV-2 showed higher sensitivity to arginine than HHV-1.

Although the target sites of arginine in its virucidal effect have not yet been determined, the observed requirement of a high concentration suggests that arginine does not act on a specific site of the virion with high affinity, but likely interacts with multiple sites of the virion with low affinity (i.e., non-specific sites), affecting structures of virion proteins, protein-protein interactions of envelope glycoproteins and glycoprotein-lipid interactions on the viral envelope. Reported characteristics of arginine (such as solubilization of inclusion body or suppression of hydrophobic and aromatic interactions between proteins) also support this notion $(1,18)$. Considering that antiviral drugs with a specific target inevitably generate drug-resistant variants by the mutation of the drug-binding site of the target protein molecule, the non-specific, multiple target sites of arginine are unlikely to generate resistant viruses and provide a unique and obvious advantage for arginine over the conventional antiviral drugs.

In addition to these virucidal effects, arginine is capable of inhibiting in vitro multiplication of HHV-2 (Fig. 5). Since in vitro cell based assays do not contain immune cells, the results clearly demonstrate the direct action of arginine on the growth suppression of HHV-2. Although the primary arginine-sensitive step in the HHV-2 multiplication remains unclear, the time of addition experiments demonstrated that the addition of arginine after the completion of viral DNA replication (at $6 \mathrm{~h}$ p.i.) or even at the later stages of the infection (such as 8-12 h p.i.) may still inhibit the normal progeny virus formation to a significant extent, while earlier addition of arginine nearly completely suppressed viral growth. It remains unclear how arginine suppresses the progeny virus production in the HHV-2-infected cells, although a proposal has been made that arginine affects virus growth through its effects on certain cellular enzymes $(19,20)$.

Whatever the mechanism involved, arginine does have antiviral activities against HHV-2 at moderate concentrations. However, it is impossible to achieve such high serum arginine concentrations and, thus, to use arginine as an antiviral drug against systemic infections. However, such concentrations may be readily achieved in topical applications against superficial viral infections. HHV-2 and a number of other viruses cause serious topical diseases on the body surface and hence antiviral activities of arginine may be applied in these areas. Lack of the possibility of generating drug-resistant variants as well as low cost offer great advantages particularly for preventive use.

\section{Acknowledgements}

The authors thank Dr Daisuke Ejima (Ajinomoto, Japan) for his helpful discussion.

\section{References}

1. Arakawa T, Uozaki M and Koyama AH: Modulation of small molecule solubility and protein binding by arginine. Mol Med Rep 3: 833-836, 2010.

2. Yamasaki H, Tsujimoto K, Koyama AH, Ejima D and Arakawa T: Arginine facilitates inactivation of enveloped viruses. J Pharm Sci 97: 3067-3073, 2008.

3. Utsunomiya H, Ichinose M, Tsujimoto K, Katsuyama $Y$, Yamasaki H, Koyama AH, Ejima D and Arakawa T: Co-operative thermal inactivation of human herpes simplex virus and influenza virus by arginine and $\mathrm{NaCl}$. Int $\mathrm{J}$ Pharm 366: 99-102, 2009

4. Arakawa T, Kita Y and Koyama AH: Synergistic virus inactivation effects of arginine. Biotechnol J 4, 174-178, 2009.

5. Tsujimoto K, Uozaki M, Ikeda K, Yamasaki H, Utsunomiya H, Ichinose M, Koyama AH and Arakawa T: Solvent-induced virus inactivation by acidic arginine solution. Int $\mathrm{J}$ Mol Med 25: 433-437, 2010.

6. Katsuyama Y, Yamasaki H, Tsujimoto K, Koyama AH, Ejima D and Arakawa T: Butyroyl-arginine as a potent virus inactivation agent. Int J Pharm 361: 92-98, 2008.

7. Brorson K, Krejci S, Lee K, Hamilton E, Stein K and Xu Y: Bracketed generic inactivation of rodent retroviruses by low $\mathrm{pH}$ treatment for monoclonal antibodies and recombinant proteins. Biotechnol Bioeng 82: 321-329, 2003.

8. Ikeda K, Yamasaki H, Suzuki Y, Koyama AH and Arakawa T: New strategy with acidic arginine solution for the treatment of influenza A virus infection: Review. Exp Ther Med 1: 251-256, 2010.

9. Ikeda K, Yamasaki H, Minami S, Naito T, Irie H, Arakawa T and Koyama AH: Virucidal ability of arginine and its possible application as an antiherpetic agent. In: From the Hallowed Halls of Herpesvirology. Baines J and Blaho J (eds). Imperial College Press, London, pp435-449, 2011.

10. Naito T, Irie H, Tsujimoto K, Ikeda K, Arakawa T and Koyama AH: Antiviral effect of arginine against herpes simplex virus type 1. Int J Mol Med 23: 495-499, 2009.

11. Roizman B, Knipe DM and Whitley RJ: Herpes simplex viruses. In: Knipe DM and Howley PM (eds). Fields Virology. 5th edition. Lippincott Williams and Wilkins, Philadelphia, pp2501-2601, 2007.

12. Koyama AH and Miwa Y: Suppression of apoptotic DNA fragmentation in herpes simplex virus type 1-infected cells. J Virol 71: 2567-2571, 1997.

13. Koyama AH, Akari H, Adachi A, Goshima F and Nishiyama Y: Induction of apoptosis in HEp-2 cells by infection with herpes simplex virus type 2. Arch Virol 143: 2435-2441, 1998.

14. Koyama AH and Uchida T: The effect of ammonium chloride on the multiplication of herpes simplex virus type 1 in Vero cells. Virus Res 13: 271-281, 1989.

15. Koyama AH, Arakawa T and Adachi A: Acceleration of virusinduced apoptosis by tumor necrosis factor. FEBS Lett 426: $179-182,1998$.

16. Hata S, Koyama AH, Shiota H, Adachi A, Goshima F and Nishiyama Y: Antiapoptotic activity of herpes simplex virus type 2: A role of US3 protein kinase gene. Microbe Infect 1: 601-607, 1999.

17. Koyama AH and Uchida T: Quantitative studies on the maturation process of herpes simplex virus type 1 in Vero cells. Virus Res 10: 281-285, 1988.

18. Arora D and Khanna N: Method for increasing the yield of properly folded recombinant human gamma interferon from inclusion bodies. J Biotechnol 52: 127-133, 1996.

19. Takada H, Kishimoto C, Hiraoka Y and Ochiai H: Oral L-arginine prevents murine coxsackievirus B3 myocarditis. Int J Cardiol 86: 272-279, 2002.

20. Agawa H, Ikuta K, Minamiyama Y, Inoue $M$ and Sairenji T: Down-regulation of spontaneous Epstein-Barr virus reactivation in the P3HR-1 cell line by L-arginine. Virology 304: 114-124, 2002. 